Article

\title{
Compost Inoculated with Fungi from a Mangrove Habitat Improved the Growth and Disease Defense of Vegetable Plants
}

\author{
Fuad Ameen * and Ali A. Al-Homaidan
}

Citation: Ameen, F.; Al-Homaidan, A.A. Compost Inoculated with Fungi from a Mangrove Habitat Improved the Growth and Disease Defense of Vegetable Plants. Sustainability 2021, 13, 124. https://dx.doi.org/10.3390/ su13010124

Received: 20 November 2020 Accepted: 19 December 2020 Published: 24 December 2020

Publisher's Note: MDPI stays neutral with regard to jurisdictional claims in published maps and institutional affiliations.

Copyright: (c) 2020 by the authors. Licensee MDPI, Basel, Switzerland. This article is an open access article distributed under the terms and conditions of the Creative Commons Attribution (CC BY) license (https: / / creativecommons.org / licenses/by/4.0/).
Department of Botany and Microbiology, College of Science, King Saud University, Riyadh 11451, Saudi Arabia; homaidan@KSU.EDU.SA

* Correspondence: fuadameen@ksu.edu.sa
Abstract: Municipal organic wastes could be exploited as fertilizers, having been given the ability to suppress plant diseases by the inoculation of the waste with certain fungi in the composting process. Our aim was to develop a novel fertilizer using composting in combination with fungi associated with mangrove forests. Nine fungal species were isolated from a mangrove forest habitat and screened for their activity against five phytopathogenic fungi, their plant-growth promotion ability, and their phosphate solubilization ability. Two fungal isolates, Penicillium vinaceum and Eupenicillium hirayama, were inoculated into organic waste before the composting experiment. After 90 days, the physico-chemical properties of the compost (color, moisture, $\mathrm{pH}, \mathrm{C}: \mathrm{N}$ ratio and cation exchange capacity (CEC)) indicated the maturity of the compost. The C:N ratio decreased and the CEC value increased most in the compost with the inoculum of both mangrove fungi. The vegetable plants grown in the mangrove fungi-inoculated composts had a higher vigor index than those grown in the control compost. The seeds collected from the plants grown in the fungi-inoculated composts had higher disease defense ability than the seeds collected from the control compost. The results indicated that the properties of the fungi shown in vitro (antagonistic and plant-growth promotion) remained in the mature compost. The seeds of the plants acquired disease defense ability, which is a remarkable observation that is useful in sustainable agriculture.

Keywords: municipal waste; biological fertilizer; phytopathogens; sustainable agriculture; organic waste treatment

\section{Introduction}

Organic wastes from communities are still largely dumped or burned worldwide. In landfills, organic waste is degraded to methane and carbon dioxide, two of the many gases that are responsible for climate change. Burning instead produces harmful gaseous emissions, and the nutrients the waste contains are lost. In order to be able to return the valuable nutrients to agricultural soils, novel practices without huge investments in waste management are needed. When organic wastes are sorted, treated, and used in agriculture locally, many benefits are reached, especially in the areas of rapid population growth. One area where almost all municipal solid wastes are dumped in landfills is Saudi Arabia [1]. About $40 \%$ of the waste dumped is organic, and composting as a waste management practice is limited to small experiments [2].

The composting of organic wastes diminishes the environmental problems of waste disposal, and it has several other benefits. The addition of compost to farmland improves the fertility of the soil by increasing the amount of nutrients available to plants and organic matter. Organic matter, in turn, improves the water-holding capacity of soil. Farming in sandy desert areas, such as in Saudi Arabia, is totally based on irrigation [3] and, therefore, the development of organic waste recycling in these farmlands is of crucial importance.

The plant-growth promotion after the addition of compost is well known in agricultural fields [3-5]. Furthermore, the disease suppression ability of compost has been recognized recently [6,7]. Microbes not only transform the waste into fertile compost but 
also, when certain microbes are used in the composting, the microbes themselves might provide benefits. This has been observed previously. Certain microbial inoculums have been observed to enhance the microbial activity and speed the composting process, as well as being observed to enhance the soil suppressiveness against pathogens [8-11]. However, more information about potential beneficial microbes is needed. One habitat where such useful active microbes might be common is mangrove forests. Mangrove fungi, such as Trichoderma viride and Steptomyces sp., have been shown to promote plants' growth [12,13]. Moreover, the inhibition of phytopathogens has been observed for mangrove-associated fungi [14]. Phytopathogens such as Pythium aphanidermatum, Fusarium solani and Rhizoctonia solani were inhibited by fungi isolated from a mangrove habitat [14-16]. Therefore, we chose the mangrove forest habitat to search for beneficial fungi in composting.

Compost must be mature in order to be non-toxic to plants [17]. This can be assessed by its color, and by measuring its $\mathrm{pH}, \mathrm{C}: \mathrm{N}$ ratio, and cation exchange capacity [18]. In searching for beneficial fungi in composting, the enzyme activities, activities against phytopathogens, and plant-growth promotion abilities are useful to screen. The measurement of the activity against phytopathogens can be carried out with a traditional dual culture method. The biological disease control potential can be assessed as hydrogen cyanide production [19]. The plant growth promotion can be assessed as the production of plant hormones, such as indole acetic acid and gibberellic acid [20,21]. Phosphate solubilization ability of the microbes is useful to assess because it would be beneficial in sustainable agriculture [22].

Our aim was to develop a fertilizer that promotes vegetable plant growth and suppresses plant diseases by modifying the composting process. We inoculated waste with mangrove-associated fungi and assessed the final product for its ability to improve plant (pepper, aubergine and tomato) growth and suppress phytopathogens. Moreover, we took a novel approach in which we assessed the ability of the plants grown in the compost to produce seeds that defend themselves against phytopathogens.

\section{Materials and Methods}

\subsection{Preliminary Screening for Mangrove-Associated Fungi}

We isolated fungi from a mangrove habitat and screened their enzyme activities, activity against phytopathogens, and plant-growth promotion ability. Floating debris and sediment were separately collected $40 \mathrm{~km}$ south of Jeddah and $45 \mathrm{~km}$ south of Jazan on the Saudi Red Sea coast (Figure 1) in May 2018. The dominant mangrove species was Avicennia marina [23]. The samples were collected in sterile bottles and transported in an icebox to the laboratory.

The homogenized fresh sediment $(1 \mathrm{~g})$ was mixed with $1 \mathrm{~mL}$ of distilled water and $100 \mu \mathrm{L}$ Tween-20, and inoculated in a serial dilution on MF1 medium [10] with dextrose $\left(20 \mathrm{~g} \mathrm{~L}^{-1}\right)$ as a carbon source and streptomycin $\left(500 \mathrm{mg} \mathrm{L}^{-1}\right)$ to avoid bacterial growth.

The plant material of the debris samples was first surface-sterilized with $2.5 \%$ hypochlorite for $2 \mathrm{~min}$. After washing with sterile distilled water, small pieces of debris were placed on MF1 medium. All of the plates were incubated at $30 \pm 2{ }^{\circ} \mathrm{C}$ for $5-7$ days and the pure cultures were collected for further studies. All of the chemicals and reagents used in the present study were of analytical grade, and were procured from Sigma Aldrich (St. Louis, $\mathrm{MO}, \mathrm{USA})$. 


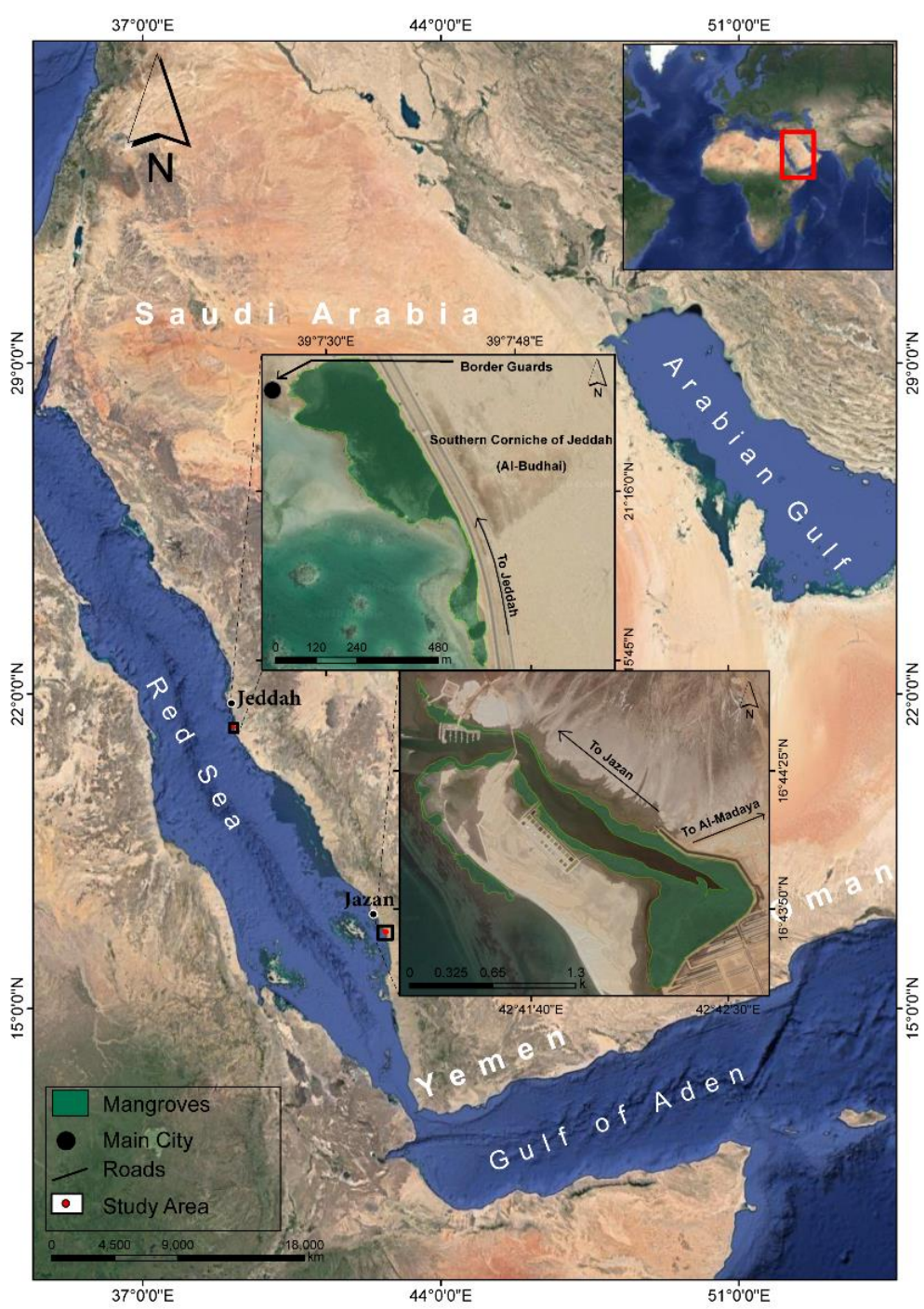

Figure 1. Two sampling sites along the Red Sea Coast.

\subsubsection{Activity against Phytopathogens}

The ability of mangrove fungi to inhibit phytopathogens was measured using the dual-culture technique. The plant pathogens Fusarium oxysporum, F. solani, Aspergillus flavus, A. niger, and Bipolaris oryzae-stored King Saud University, Department of Botany and Microbiology (Saudi Arabia) — and nine mangrove fungal isolates (Aspergillus nomius; A. terreus; Alternaria alternata; Cladosporium sphaerospermum; E. hirayamae; Geosmithia pallida; P. vinaceum; Paecilomyces variotii and Phialophora alba) were inoculated on potato dextrose agar (PDA). All of the combinations of five pathogens and nine mangrove fungi were prepared by placing mycelia plugs $(5 \mathrm{~mm})$ on petri dishes $(90 \mathrm{~mm})$ with $6 \mathrm{~cm}$ distance from each other. After a five days of incubation, the plates on which the phytopathogens did not grow or grew slowly were chosen for further study.

\subsubsection{Plant-Growth Promotion}

The indole acetic acid (IAA) production method was adopted from Khan et al. [24]. The indole acetic acid (IAA) production was confirmed with High Performance Liquid Chromatography (HPLC). The agar plugs of mangrove fungi were transferred aseptically to an Erlenmeyer flask (1 L) containing $500 \mathrm{~mL}$ PD broth containing $0.2 \%$ tryptophan, and were incubated at room temperature with shaking at $110 \times g$ for 10 days. The culture broth was centrifuged at $10,000 \times g$ for $10 \mathrm{~min}$ and the supernatant was collected. The culture filtrate was extracted twice with an equal volume of ethyl acetate, and the organic phase 
was concentrated by the use of a rotary evaporator below $40{ }^{\circ} \mathrm{C}$ in order to obtain the crude extract powder [25]. The resultant crude extract was collected and re-suspended in methanol. The HPLC (Merck KGaA, Darmstadt, Germany) analysis was performed using a mixture of methanol and water containing $0.5 \%$ acetic acid in the ratio of $60: 40$ with a flow rate of $1 \mathrm{~mL} / \mathrm{min}$ at $280 \mathrm{~nm}$. For the gibberellic acid confirmation, the fungi were incubated in Czapek dox broth, as above. The HPLC analysis of the extract prepared as above was performed using acetonitrile and $0.01 \% \mathrm{H}_{3} \mathrm{PO}_{4}$ in water $(60: 40)$ with a flow rate of $0.6 \mathrm{~mL} / \mathrm{min}$ at $206 \mathrm{~nm}$ [26].

The hydrogen cyanide production was measured by inoculating the fungal cultures onto PDA containing $4.4 \mathrm{~g} / \mathrm{L}$ glycine [27]. A Whatman filter paper no.1 soaked in $0.5 \%$ picric acid in $2 \% \mathrm{Na}_{2} \mathrm{CO}_{3}$ was placed on the plate. The plates were sealed and incubated at $30{ }^{\circ} \mathrm{C}$ for 4 days. The color change of the filter paper from yellow to red was considered to be a positive result. Un-inoculated growth medium was used as negative control.

The 1 aminocyclopropane-1-carboxylic acid (ACC) deaminase production of the isolates was screened using Dworkin-Foster's (DF) salt minimal medium $\left(4 \mathrm{~g} \mathrm{~L}^{-1} \mathrm{KH}_{2} \mathrm{PO}_{4}\right.$, $6 \mathrm{~g} \mathrm{~L}^{-1} \mathrm{Na}_{2} \mathrm{HPO}_{4}, 0.2 \mathrm{~g} \mathrm{~L}^{-1} \mathrm{MgSO}_{4} \cdot 7 \mathrm{H}_{2} \mathrm{O}, 1 \mathrm{mg} \mathrm{L}{ }^{-1} \mathrm{FeSO}_{4} \cdot \mathrm{H}_{2} \mathrm{O}, 10 \mu \mathrm{g} \mathrm{L}{ }^{-1} \mathrm{H}_{3} \mathrm{BO}_{3}$, $10 \mu \mathrm{g} \mathrm{L}^{-1} \mathrm{MnSO}_{4}, 70 \mu \mathrm{g} \mathrm{L}{ }^{-1} \mathrm{ZnSO}_{4}, 50 \mu \mathrm{gL}^{-1} \mathrm{CuSO}_{4}, 10 \mu \mathrm{g} \mathrm{L}^{-1} \mathrm{MoO}_{3}, 2 \mathrm{~g} \mathrm{~L}^{-1}$ glucose, $2 \mathrm{~g} \mathrm{~L}^{-1}$ gluconic acid, $2 \mathrm{~g} \mathrm{~L}^{-1}$ citric acid, $12 \mathrm{~g} \mathrm{~L}^{-1}$ agar) amended with $0.2 \%(w / v)$ $\left(\mathrm{NH}_{4}\right) 2 \mathrm{SO}_{4}$ [28]. The growth of this medium after 4 days of incubation was considered to be a positive result.

The phosphate solubilization was analyzed using Pikovskaya medium (HiMedia Laboratories, Bengaluru, India) containing $2.4 \mathrm{mg} / \mathrm{mL}$ bromophenol blue [29]. The media inoculated with the isolates were incubated for $48 \mathrm{~h}$ and observed for the formation of the yellow zone around the colony indicating phosphate solubilization.

\subsubsection{Extracellular Enzyme Activity}

The extracellular enzyme (cellulase, laccase, lipase, protease, amylase and chitinase) activities of the isolates were screened using the methods based on culturing the microbes on different media, as described by Maria et al. [30].

\subsubsection{Molecular Identification of Fungi}

The isolates were incubated in $50 \mathrm{~mL}$ potato dextrose broth (PDB) at room temperature for 5 days in an orbital shaker. The fungal mycelia $(500 \mathrm{mg})$ were weighed for the total genomic DNA analysis, as described by White et al. [31]. ITS1 (5'-TCC gTA ggT gAA CCT gCg g- $\left.3^{\prime}\right)$ and ITS4 (5'-TCC TCC gCT TAT TgA TAT gC- $\left.3^{\prime}\right)$ primers were used. PCR was performed with an initial denaturation at $95^{\circ} \mathrm{C}$ for $5 \mathrm{~min}$, followed by 35 cycles of denaturation at $94{ }^{\circ} \mathrm{C}$ for $1 \mathrm{~min}$, annealing at $55.5^{\circ} \mathrm{C}$ for $2 \mathrm{~min}$, extension at $72{ }^{\circ} \mathrm{C}$ for $2 \mathrm{~min}$, and a final extension at $72^{\circ} \mathrm{C}$ for $10 \mathrm{~min}$. The amplified product was checked in $1.2 \%(w / v)$ agarose gel, purified using a cleanup kit (Mo-Bio Ultra Clean) and used for the DNA sequencing (Genetic analyzer 3130-Applied Bio-systems). The sequence data were analyzed with BLAST software.

\subsection{Composting Experiment}

We chose two isolates of mangrove fungi and carried out an experiment in order to produce compost. We assessed the ability of the compost to improve the soil fertility and suppress phytopathogens, as well as the ability of the plants grown in the compost to produce seeds that defend themselves against phytopathogens.

Raw materials and organic wastes-namely hay, leaves, fruit wastes, newspaper, vegetable wastes, rice husks and wheat straw-were collected and stored in the laboratory. The wastes (400 g each) were sterilized in a conical flask $\left(1000 \mathrm{~mL}^{-1}\right)$. Three replicates of the treatments with two mangrove fungal isolates ( $P$. vinaceum and E. hirayamae), their combination, and a control (Sterilized compost) were prepared. In addition, an unsterilized control treatment was prepared. The wastes were inoculated with the spore suspensions of 
the mangrove fungi, at $5 \% v / v$ for the single fungi treatments and $2.5 \% v / v$ each for the combined treatment. All of the flasks were incubated at $30 \pm 2{ }^{\circ} \mathrm{C}$ for three months.

\subsubsection{Physio-Chemical Properties}

The color of the compost was assessed visually. The dry weight of the compost was determined at $105^{\circ} \mathrm{C}$ for $4 \mathrm{~h}$, and the loss on ignition was determined at $800{ }^{\circ} \mathrm{C}$ overnight. The $\mathrm{pH}$ was measured in distilled water (1:10; sample: water $v / v)$. The carbon and nitrogen percentage was measured according to Iqbal et al. [32] using the digestive mixture of $\mathrm{Na}_{2} \mathrm{SO}_{4}$ and $\mathrm{CuSO}_{4} \cdot 5 \mathrm{H}_{2} \mathrm{O}(10: 1)$.

The cation exchange capacity was measured using the method described by [18]. Compost $(2 \mathrm{~g})$ and $0.1 \mathrm{M} \mathrm{HCL}\left(100 \mathrm{~mL}^{-1}\right)$ were shaken for $2 \mathrm{~h}$ and precipitated with $1 \%$ silver nitrate. The solution was mixed in a flask with $0.25 \mathrm{M}$ barium acetate, shaken and titrated with $0.1 \mathrm{M} \mathrm{NaOH}$. The alkaline cations were calculated from the amount of sodium hydroxide solution used.

\subsubsection{Plant-Growth Promoting Activity}

The seeds of Capsicum annuum (pepper), Solanum melongena (aubergine) and S. lycopersicum (tomato) were first surface-sterilized in $2 \% \mathrm{NaOCl}$ (bleach) for $1 \mathrm{~min}$, washed several times with sterile distilled water, immersed in $70 \%$ ethanol, and finally rinsed three times with sterile distilled water in order to remove epiphytes. The efficiency of the surface sterilization was confirmed by spreading $100 \mu \mathrm{L}$ of the last rinse water onto PDA, which was then incubated for 14 days. The surface-sterilized seeds were placed on sterile filter paper to dry for $20 \mathrm{~min}$.

The seeds were placed on tissue paper on petri dishes and saturated with sterile distilled water for germination. After 5 days, the germinated seeds were transferred into plastic black pots (10 replicates) with compost. At the ripening stage after 60 days, the root length and shoot length were measured manually, and the leaf number, number of fruits, and number of seeds were counted. The dry mass and wet mass were monitored. For the vigor index, the mean root length and the mean shoot length were summed and multiplied by the percentage of the seeds germinated.

\subsubsection{Disease Defense Ability of Seeds}

The seeds from the fruits of the plants grown (as explained above) in the mature composts were collected. In total, 10 seeds of S. lycopersicum, 20 seeds of S. melongena and 50 seeds of $C$. annuum were placed as three replicates on petri dishes and exposed to the spore suspensions of $(5 \% v / v)$ of four plant pathogens F. solani, F. oxysporum, A. flavus, and $B$. oryzae, separately. The germinated seeds were calculated after $48 \mathrm{~h}$, which indicated the disease defense ability of the seeds.

\subsection{Statistical Analysis}

A two-way analysis of variance (ANOVA) (P. vinaceum and E. hirayamae and their interaction) was carried out in order to find out the effect of the mangrove fungi on the quality of the compost. In addition, a $t$-test was carried out in order to compare the sterilized control and the unsterilized control. $p<0.05$ was considered to be a significant effect. RStudio Version (3.5.1) was used [33]. The data were log transformed when needed (tested using Shapiro-Wilk test) in order to fulfil the assumptions.

\section{Results}

\subsection{Preliminary Screening of the Fungal Isolates}

Two isolates, P. vinaceum (Accession No. KP033201) and E. hirayamae (Accession No. KM979606), showed the highest antifungal, enzymatic and plant-growth promotion activities in vitro. Penicillium vinaceum had relatively high antifungal activity against the plant pathogens F. oxysporum, A. flavus, B. oryzae, and F. solani (Table 1). Eupenicillium hirayamae showed activity against $A$. niger. 
Table 1. In vitro activity of nine fungi isolated from a mangrove habitat against five fungal phytopathogens, measured as the zone of inhibition (mm). - indicates no inhibition.

\begin{tabular}{|c|c|c|c|c|c|}
\hline Mangrove Fungi & Fusarium oxysporum & Aspergillus niger & Aspergillus flavus & Bipolaris oryzae & Fusarium solani \\
\hline Positive control & $12 \pm 0.18$ & $13 \pm 0.11$ & $10 \pm 0.14$ & $11 \pm 0.13$ & $14 \pm 0.19$ \\
\hline E. hirayamae & $16 \pm 0.10$ & $18 \pm 0.18$ & $18.5 \pm 0.10$ & $14.2 \pm 0.12$ & $17 \pm 0.11$ \\
\hline C. sphaerospermum & - & - & - & - & $10 \pm 0.21$ \\
\hline A. terreus & $8 \pm 0.23$ & $4 \pm 0.21$ & - & - & - \\
\hline P. vinaceum & $17 \pm 0.12$ & $14 \pm 0.13$ & $19 \pm 0.21$ & $15 \pm 0.12$ & $19 \pm 0.13$ \\
\hline P. alba & - & - & $6 \pm 0.23$ & - & $8 \pm 0.21$ \\
\hline G. pallida & $1.5 \pm 0.24$ & - & - & - & $4 \pm 0.25$ \\
\hline A. nomius & $5 \pm 0.14$ & - & - & $3 \pm 0.15$ & - \\
\hline A. alternata & - & $3 \pm 0.18$ & - & - & - \\
\hline P. variotii & $2.5 \pm 0.13$ & - & - & $7.5 \pm 0.17$ & - \\
\hline
\end{tabular}

Penicillium vinaceum and E. hirayamae showed strong enzyme activities, including: amylase, protease, chitinase, cellulose, and laccase (P. vinaceum only) (Table 2). Medium activity was detected for lipase (P. vinaceum and E. hirayamae) and laccase (E. hirayamae only). All of the other isolates had weak enzyme activities.

Table 2. Enzyme activities of nine fungi isolated from a mangrove habitat. +++ indicates strong activity, ++ indicates medium activity, and + indicates weak activity.

\begin{tabular}{ccccccc}
\hline Mangrove Fungi & Amylase & Protease & Chitinase & Cellulase & Laccase & Lipase \\
\hline E. hirayamae & +++ & ++ & +++ & +++ & ++ & ++ \\
C. sphaerospermum & & & & + & + & \\
A. terreus & & + & ++ & & & + \\
P. vinaceum & +++ & +++ & +++ & +++ & +++ & ++ \\
P. alba & + & & & & & + \\
G. pallida & + & + & & & & \\
A. nomius & + & & & & \\
A. alternata & & + & & & \\
P. variotii & & & & & \\
\hline
\end{tabular}

Penicillium vinaceum and E. hirayamae showed potential plant-growth promotion abilities. The IAA and gibberellic acid production of both $P$. vinaceum and E. hirayamae were observed (Table 3) and confirmed by HPLC analysis. Moreover, these isolates also showed phosphate solubilization activity and hydrogen cyanide production.

Table 3. Variables indicating the plant-growth promotion activity of fungi isolated from a mangrove habitat. +++ indicates strong activity, ++ indicates medium activity, + indicates weak activity, and - indicates no activity.

\begin{tabular}{ccccc}
\hline Mangrove Fungi & Acc Deaminase & IAA Production & Phosphate Solubilization & HCN Production \\
\hline E. hirayamae & +++ & +++ & +++ & ++ \\
C. sphaerospermum & + & + & - & - \\
A. terreus & + & - & +++ & - \\
P. vinaceum & +++ & +++ & - & + \\
P. alba & - & + & - & - \\
G. pallida & + & + & - & - \\
A. nomius & + & + & - & - \\
A. alternata & - & + & - & - \\
P. variotii & - & & \\
\hline
\end{tabular}

\subsection{Composting Experiment}

After 12 days of incubation, the volume of the compost decreased and decoloration appeared. After 90 days of incubation, the color of the compost was changed to a blackish- 
brown in the fungal treatments; in the sterilized control, the color was a light brown; and in the unsterilized control, it was brown. For each physico-chemical variable (Table 4), the twoway ANOVA indicated that both of the fungal treatments (P. vinaceum and E. hirayamae) had significant effects. The interaction term was not significant, indicating that the combination treatment with the two fungi was not more effective than the single-fungus treatments. The moisture percentage of the mangrove fungi-treated samples was $20 \%$ higher than that of sterilized control (Table 4). The $\mathrm{pH}$ of the fungi-treated samples was 7.4-7.5, and whereas in the sterilized control it was 7 . The total $\mathrm{N}_{2} \%$ was more than doubled in fungal treatments (5.0-5.4\%) compared to the sterilized control $(2.4 \%)$, and conversely, the C:N ratio was more than doubled in sterilized control (17.9). The cation exchange capacity value was almost doubled in the fungal treatments $\left(65 \mathrm{cmolc} \mathrm{kg}^{-1}\right)$ compared to the sterilized control $\left(34 \mathrm{cmolc} \mathrm{kg}{ }^{-1}\right)$. The results of the unsterilized control were set between the sterilized control and the fungal treatments. The $t$-test showed significant differences for moisture, $\mathrm{N}, \mathrm{C}: \mathrm{N}$ ratio and CEC results, which were all, however, nearer to the sterilized control than the fungal treatments.

Table 4. Physico-chemical properties of the composts produced by inoculating two individual mangrove fungi (E. hirayamae and $P$. vinaceum) and their combination in comparison to a sterilized waste control. The unsterilized control refers to the treatment of raw waste. * indicates a significant effect $(p<0.05)$ of the fungal species, or a significant interaction (combined effect) in a two-way ANOVA. An 'a' indicates a significant difference between the two control treatments $(t$-test).

\begin{tabular}{|c|c|c|c|c|c|}
\hline Treatment & E. hirayamae & P. vinaceum & $\begin{array}{l}\text { E. hirayamae } \\
\text { P. vinaceum }\end{array}$ & Sterilized Control & Unsterilized Control \\
\hline \multicolumn{6}{|c|}{ Compost property } \\
\hline Color & Blackish brown & Blackish brown & Blackish brown & Light brown & Brown \\
\hline Moisture (\%) & $38 *$ & $40 *$ & 40 & 12 & $20 \mathrm{a}$ \\
\hline $\mathrm{pH}$ & $7.5^{*}$ & $7.4 *$ & 7.4 & 7.0 & 7.2 \\
\hline $\mathrm{OM}(\%)$ & $33 *$ & $36^{*}$ & 34 & 43 & 40 \\
\hline $\mathrm{N}(\%)$ & $5.1^{*}$ & $5.0 *$ & 5.4 & 2.4 & $3.0 \mathrm{a}$ \\
\hline $\mathrm{C}: \mathrm{N}$ ratio & $6.4^{*}$ & $7.2 *$ & 6.2 & 17.9 & $13.3 \mathrm{a}$ \\
\hline $\operatorname{CEC}\left(\operatorname{cmol}(+) \mathrm{kg}^{-1}\right)$ & $64 *$ & $65 *$ & 64 & 34 & $39 a$ \\
\hline
\end{tabular}

All of the plant-growth promotion measures were higher in the fungal treatments than in the sterilized control, as seen from the values relative to the sterilized control (Figure 2). Most values were also higher in unsterilized than unsterilized control. For the vigor index, the two-way ANOVA showed the significant effects of P. vinaceum and E. hirayamae, as well as their significant interaction for the three plant species (Figure 3). The highest vigor index was observed for S. melongena (5200) in the combined treatment of the two fungal species. The single fungal treatments gave about $25 \%$ lower indices. For comparison, in the sterilized control, the vigor index was less than half that of the combined treatment (2000). The $t$-test showed no difference in the vigor index between the sterilized control and the unsterilized control.

The disease incidence of the plants grown in the composts was $60-70 \%$ in the unsterilized control and 50-70\% in the sterilized control (Table 5). For each plant species, the difference was significant ( $t$-test). However, the difference was not consistent within the plant species. For S. melongena, the disease incidence was higher, whereas for the other two plant species it was lower in the sterilized control than in the unsterilized control. The two-way ANOVA indicated significant effects for both P. vinaceum and E. hirayamae, as well as a significant interaction. In the combined treatment, the disease incidence was $0 \%$ for each plant species. For other fungi and plant species, the disease incidence varied between $10 \%$ and $20 \%$. 


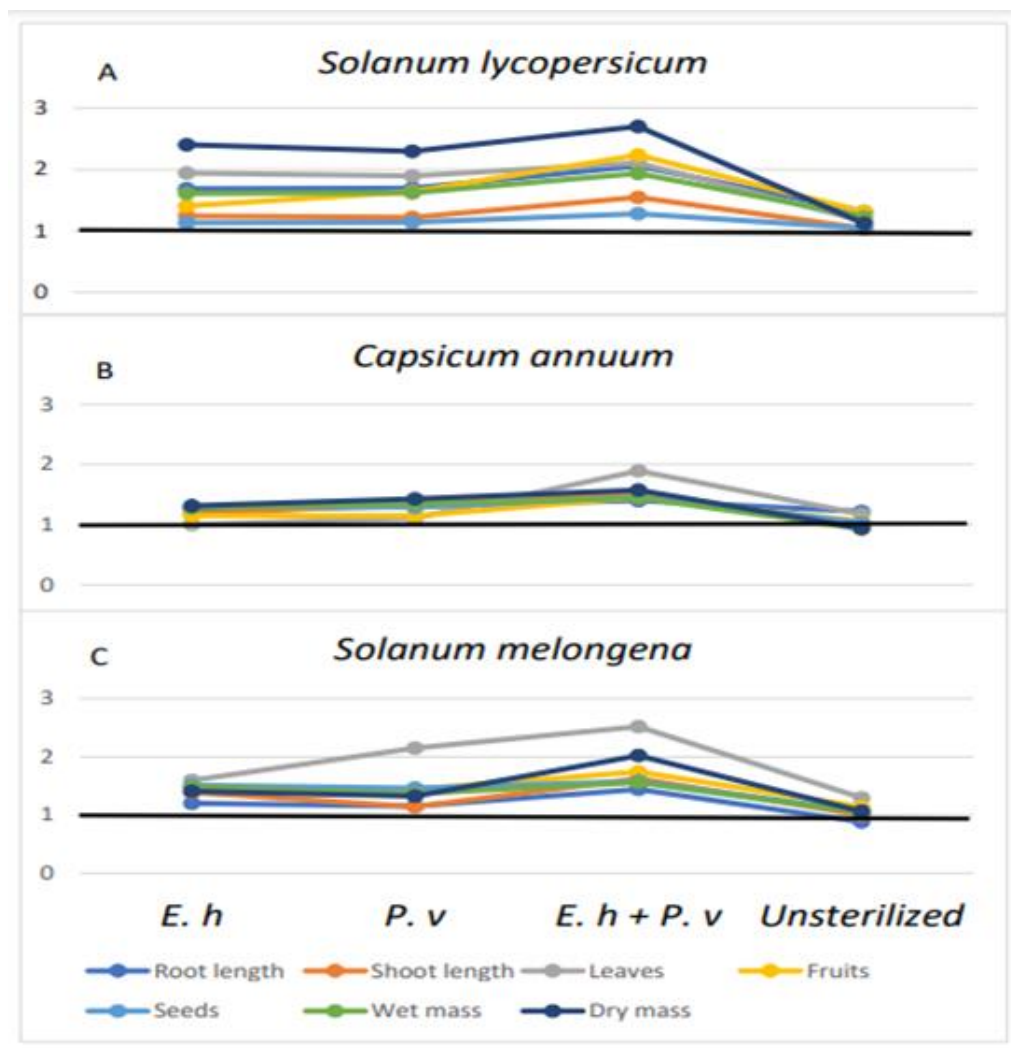

Figure 2. Relative plant growth variables (mean, $n=3,0.01<\mathrm{SD}<0.4$ ) in the different composting treatments. Sterilized control $=1$. The treatments refer to E. hirayamae, P. vinaceum, E. hirayamae + P. vinaceum, and the unsterilized control.

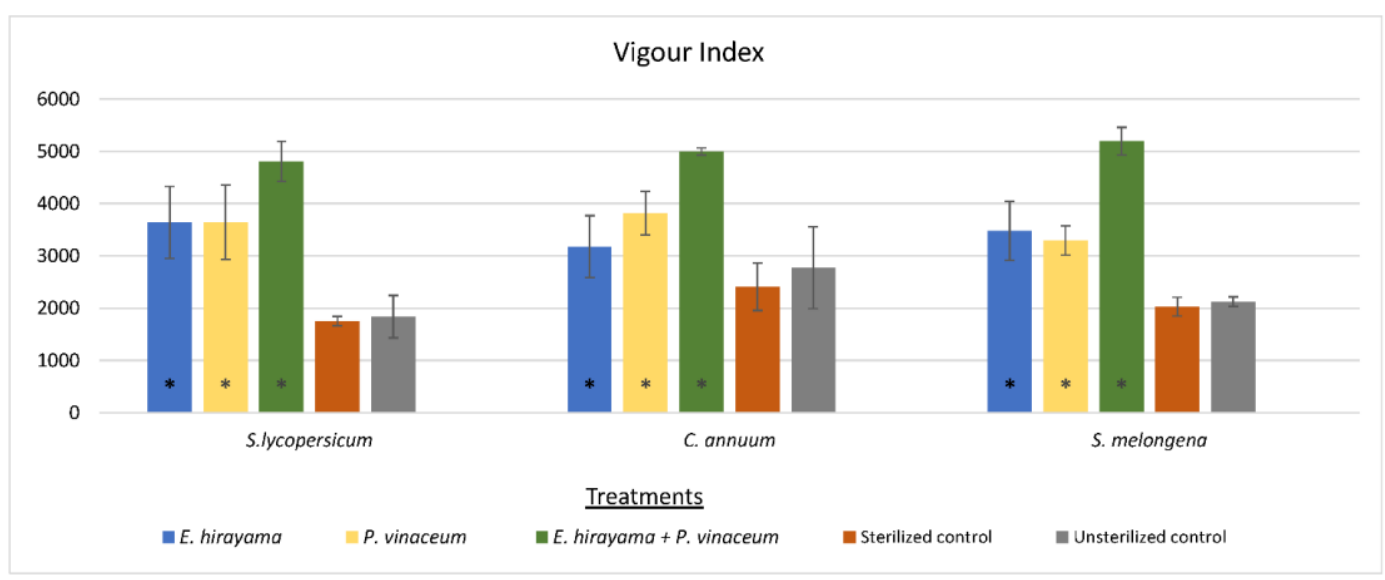

Figure 3. Vigor index of three plants (S. lycopersicum, C. annuum, S. melongena) grown in the composts inoculated with two mangrove fungi (P. vinaceum and E. hirayamae) and their combination compared to sterilized waste control. Unsterilized control refers to the treatment of raw waste. * indicates a significant effect $(p<0.05)$ of the fungal species or a significant interaction (combined effect) in two-way ANOVA (no significant effects was observed). a indicates a significant difference between the sterilized and unsterilized control treatments $(t$-test, $p<0.05)$.

The disease defense ability of the seeds produced by the plants grown in the composts was assessed with a seed germination test after exposure to plant pathogens. The germination test gave similar results for each plant species and all of the pathogens (Figure 4). The germination was, in general, clearly higher in the fungal treatments than in the control treatments, with the combined fungal treatment being the highest. The only non-significant effects of P. vinaceum and E. hirayamae were for the combination of the plant S. lycopersicum and 
the pathogen F. oxysporum. The interaction term was significant except for the combination of the plant S. melongena and the pathogen F. oxysporum. Only in three cases did the unsterilized control and the sterilized control differ significantly in the $t$-test, with the unsterilized control showing a higher germination percentage. The germination varied between $87 \%$ and $90 \%$ for the combined fungal treatment, and $17 \%$ and $40 \%$ in the control treatments for the plant $S$. lycopersicum. The respective values for the second plant $C$. annuum were $93-96 \%$ and $6-15 \%$, and for the third plant S. melongena, they were $87-93 \%$ and $13-25 \%$.

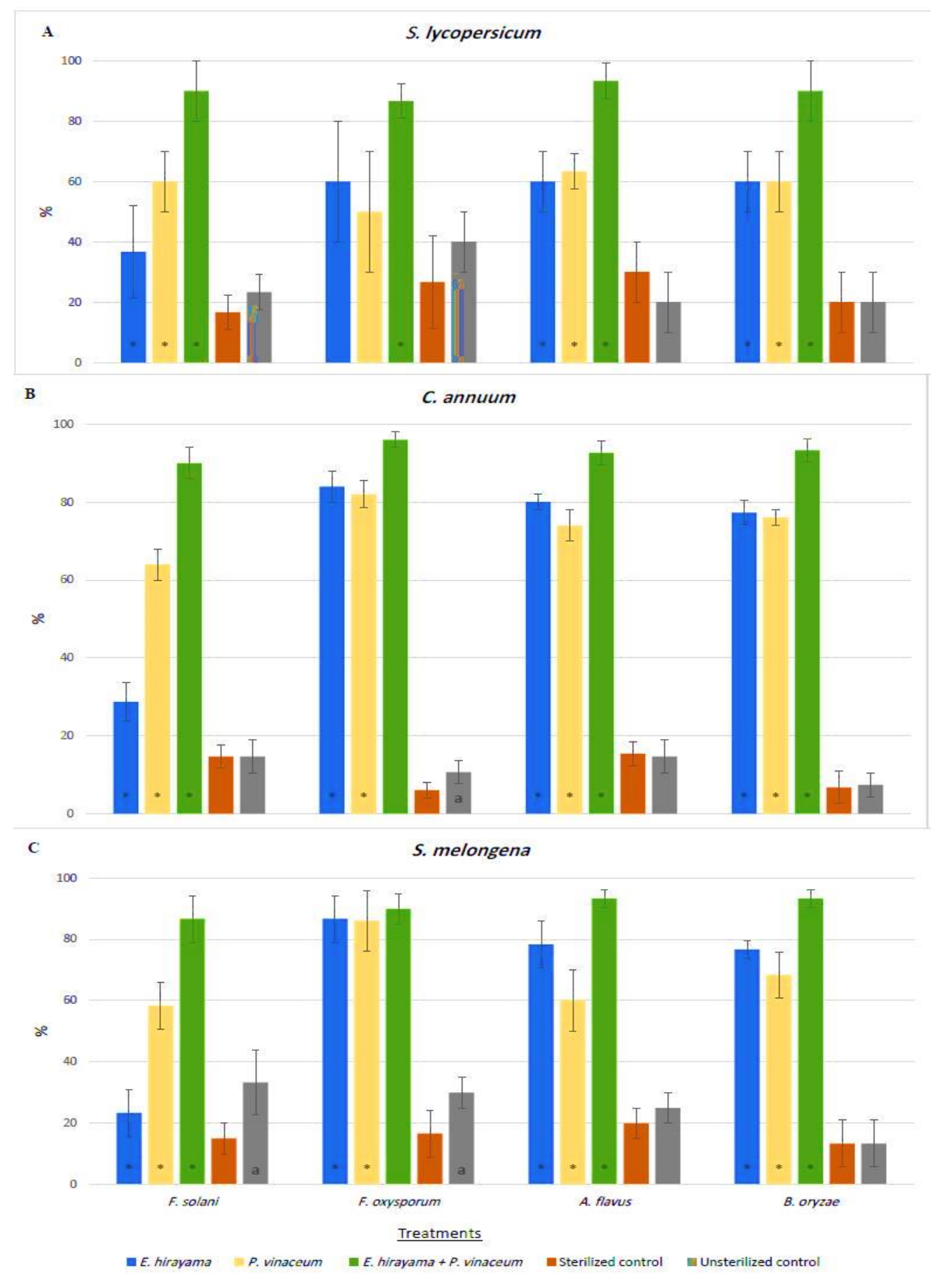

Figure 4. Germination of the seeds of three plants (S. lycopersicum, C. annuum, S. melongena) after exposure to four plant pathogens (F. solani, F. oxysporum, A. flavus, B. oryzae) and grown in the composts inoculated with two mangrove fungi (P. vinaceum and E. hirayamae) and their combination compared to sterilized waste control. Unsterilized control refers to the treatment of raw waste. * indicates a significant effect $(p<0.05)$ of the fungal species or a significant interaction (combined effect) in two-way ANOVA. a indicates a significant difference between the sterilized and unsterilized control treatments ( $t$-test, $p<0.05)$. 
Table 5. Disease incidence of the three plant species grown in the composts inoculated with two mangrove fungi (E. hirayamae and P. vinaceum) and their combination, compared to a sterilized waste control. The unsterilized control refers to the treatment of raw waste. ${ }^{*}$ indicates a significant effect $(p<0.05)$ of the fungal species and a significant interaction (combined effect) in the two-way ANOVA. An 'a' indicates a significant difference between the control treatments $(t$-test, $p<0.05)$.

\begin{tabular}{|c|c|c|c|c|c|}
\hline Treatment & Sterilized Control & E. hirayamae & P. vinaceum & E. hirayamae P. vinaceum & Unsterilized Control \\
\hline \multicolumn{6}{|l|}{ Plant species } \\
\hline S. lycopersicum & $50 \pm 5$ & $20 \pm 2 *$ & $10 \pm 2 *$ & $0 \pm 0 *$ & $60 \pm 7$ \\
\hline C. annuиm & $50 \pm 1$ & $10 \pm 3 *$ & $10 \pm 1$ * & $0 \pm 0 *$ & $70 \pm 5 a$ \\
\hline S. melongena & $70 \pm 3$ & $10 \pm 2 *$ & $10 \pm 1$ * & $0 \pm 0$ * & $60 \pm 4 \mathrm{a}$ \\
\hline
\end{tabular}

\section{Discussion}

Municipal waste composting, especially small-scale composting, provides benefits from agriculture to the circular economy $[34,35]$. The use of compost reduces the need for fertilizers in farming; compost addition has been shown to increase yields more than nitrogen, phosphorus, and potassium (NPK) chemical fertilization alone [20]. Moreover, compost has been shown to reduce many plant diseases [7,35]. We focused on further ameliorating the quality of compost by inoculating fungi into the composting process. We showed that the fungi in the compost not only increased vegetable growth remarkably but also suppressed phytopathogens. It seems that when the fungi secreted plant hormones in vitro, they improved the quality of the compost and the plants grew better. More importantly, when the fungi showed activity against phytopathogens in vitro, the seeds collected from the plants grown in the compost were able to defend themselves against the phytopathogens.

The addition of compost has been shown to improve the fertility, water holding capacity, and suppressiveness of soil against pathogens. All of these properties can be enhanced by inoculating certain microbes into the composting process. In choosing the microbes, one important aspect is the tolerance of the microbes against the harmful pollutants the waste contains, which is an aspect that has not often been considered previously. Municipal organic waste, even if it is sorted, contains small amounts of harmful materials such as plastic, heavy metals, and oil products [36]. Therefore, fungi that are not only able to tolerate pollutants but also to degrade recalcitrant materials might be useful additions to compost. Heavy-metal-tolerant organisms have been found in mangrove habitats [37,38]. In addition, recalcitrant substrates such as oil products have been shown to be degraded by mangrove habitat fungi. Nine out of 45 fungal isolates originating from a mangrove habitat were able to degrade engine oil in vitro [39]. Petroleum and cellulosic materials were degraded most efficiently by the fungal species used in this experiment, E. hirayamae [39-42]. Eupenicillium hirayamae did not efficiently degrade polyethylene, which was degraded most with a combination of fungal species [41]. In general, E. hirayamae in combination with the other fungal species, among them the one in our experiment, $P$. vinaceum, degraded the materials most efficiently [39-42]. Alternaria alternata appeared to degrade polyethene the most efficiently in a previous experiment [42]. However, in our preliminary screening of the fungi, A. alternata did not indicate any plant-growth promoting or antifungal activities in vitro.

We chose the two species showing the highest activities in vitro, as well as the ability to degrade recalcitrant materials in our previous studies. The latter property is especially important in Saudi Arabia, where plastic and other oil-based materials are common pollutants in municipal waste [43]. We inoculated waste with two fungi that were isolated from a mangrove habitat. The fungi $P$. vinaceum and E. hirayamae appeared to produce compost that doubled the yield of tomatoes, aubergines and peppers, and increased the vegetative growth of the plants by more than double. The highest increase was observed in the amount of seeds in the fruits.

Another important aspect in the assessment of the quality of a compost product is how it suppresses pathogens. Compost produced without any microbial inoculation has been 
shown to suppress many soil-borne pathogens. Fusarium sp.-caused diseases have been observed to be suppressed by different kinds of compost additions [44]. Fusarium oxysporum was suppressed by different types of compost [45]. Compost leachate was observed to suppress $A$. niger [46]. Fusarium oxysporum and $A$. niger were included in our experiment. Other pathogens-such as Pythium ultimum, Rhizoctonia solani, Phytophthora sp., Sclerotinia minor, and Verticillium dahlia-have been suppressed by the addition of different types of composts [47].

Disease suppression might be improved by the inoculation of waste with microbes. The bacterium Streptomyces sp., when used in composting, was observed to suppress several pathogens [48]. Filamentous fungi (Trichoderma, Fusarium, Gliocladium, Aspergillus and Penicillium) have also been inoculated and suppressed pathogens successfully, as reviewed recently [35]. The review did not include our mangrove-associated fungal species $P$. vinaceum and E. hirayamae, which we, therefore, can add to the list. In our experiment, the vegetables grew best in the compost in which the combination of two mangrove fungi had been inoculated to originally-sterilized wastes. Furthermore, the seeds of the most vigorous plants were able to suppress phytopathogens remarkably. To the best of our knowledge, this continuum from the plants to the seeds was reported here for the first time.

The physico-chemical properties of the composts indicated that both fungi individually and in combination produced mature compost. The lack of significant interaction between the species indicated that all of the fungal treatments produced similar compost concerning the physico-chemical properties measured. However, the microbial community in the compost has been shown to be of importance, as reviewed recently by [35]. This was observed in our study as well. Contrary to the physico-chemical variables, the biological variables gave significant interactions between the fungal species; the combined effects were showed some improvement over the others. We observed this phenomenon first for the disease incidence of the plants grown in the composts, and second for the improved germination of the seeds produced by the plants grown in the composts. This indicates that both of the microbes had a remarkable role in improving the quality of the compost. This is an important observation from a biological control point of view.

\section{Conclusions}

Composting is a far-too-seldom used technique in waste treatment, although many of its benefits have been shown. The addition of compost improves soil fertility and suppresses plant diseases, which allows the reduction of the use of chemical fertilizers and disease control agents. The properties of compost can be further ameliorated by inoculating certain microbes into the composting process, as we showed in our composting experiment. The inoculation of two mangrove fungal species improved the properties of the compost produced. We showed that the growth of vegetables increased and the phytopathogens were suppressed in the compost produced. The remarkable observation was that the ability of plants to defend themselves against phytopathogens was observed in the vegetable seeds grown in the compost. This continuum is an important observation for sustainable agriculture. Many environmental and economic benefits encourage us to take up composting as a waste treatment practice. It would be especially beneficial in areas where poor waste management facilities exist.

Author Contributions: Both authors (F.A. and A.A.A.-H.) contributed to the data analysis and the drafting of the manuscript. Both authors (F.A. and A.A.A.-H.) approved the final manuscript and are accountable for all aspects of the work. All authors have read and agreed to the published version of the manuscript.

Funding: This project was funded by the National Plan for Science, Technology and Innovation(MAARIFAH), King Abdulaziz City for Science and Technology, Kingdom of Saudi Arabia, Award Number (2-17-01-001-0051).

Conflicts of Interest: The authors declare no conflict of interest. 


\section{References}

1. Ouda, O.K.M.; Cekirge, H.M.; Raza, S.A.R. An assessment of the potential contribution from waste-to-energy facilities to electricity demand in Saudi Arabia. Energy Convers. Manag. 2013, 75, 402-406. [CrossRef]

2. Ayilara, M.S.; Olanrewaju, O.S.; Babalola, O.O.; Odeyemi, O. Waste Management through Composting: Challenges and Potentials. Sustainability 2020, 12, 4456. [CrossRef]

3. Chen, T.; Zhang, S.; Yuan, Z. Adoption of solid organic waste composting products: A critical review. J. Clean. Prod. 2020, 272, 122712. [CrossRef]

4. Adugna, G. A review on impact of compost on soil properties, water use and crop productivity. Acad. Res. J. Agric. Sci. Res. 2016, 4, 93-104.

5. Amlinger, F.; Götz, B.; Dreher, P.; Geszti, J.; Weissteiner, C. Nitrogen in biowaste and yard waste compost: Dynamics of mobilisation and availability-A review. Eur. J. Soil Biol. 2003, 39, 107-116. [CrossRef]

6. De Corato, U. Disease-suppressive compost enhances natural soil suppressiveness against soil-borne plant pathogens: A critical review. Rhizosphere 2020, 13, 100192. [CrossRef]

7. Noble, R.; Coventry, E. Suppression of soil-borne plant diseases with composts: A review. Biocontrol Sci. Technol. 2005, 15, 3-20. [CrossRef]

8. Postma, J.; Montanari, M.; van den Boogert, P.H.J.F. Microbial enrichment to enhance the disease suppressive activity of compost. Eur. J. Soil Biol. 2003, 39, 157-163. [CrossRef]

9. Sharma, A.; Sharma, R.; Arora, A.; Shah, R.; Singh, A.; Pranaw, K.; Nain, L. Insights into rapid composting of paddy straw augmented with efficient microorganism consortium. Int. J. Recycl. Org. Waste Agric. 2014, 3, 54. [CrossRef]

10. Song, C.; Zhang, Y.; Xia, X.; Qi, H.; Li, M.; Pan, H.; Xi, B. Effect of inoculation with a microbial consortium that degrades organic acids on the composting efficiency of food waste. Microb. Biotechnol. 2018, 11, 1124-1136. [CrossRef] [PubMed]

11. Sharma, A.; Saha, T.N.; Arora, A.; Shah, R.; Nain, L. Efficient Microorganism compost benefits plant growth and improves soil health in calendula and marigold. Hortic. Plant J. 2017, 3, 67-72. [CrossRef]

12. Kumar, A.; Brar, N.S.; Pal, S.; Singh, P. Available soil macro and micronutrients under rice wheat cropping system in District Tarn Taran of Punjab. Ecol. Enviton. Conserv. 2017, 23, 202-207.

13. Damare, V.S.; Kajawadekar, K.G. A preliminary study on L-asparaginase from mangrove detritus-derived fungi and its application in plant growth promotion. MycoAsia J. 2020, 4.

14. Sureshkumar, P.; Kavitha, S. Bioprospecting potential of mangrove fungus from vellar estuary, southeast coast of india for biocontrol of damping off on mustard. Res. J. Biotechnol. 2019, 14, 72-78.

15. Hamzah, T.N.T.; Lee, S.Y.; Hidayat, A.; Terhem, R.; Faridah-Hanum, I.; Mohamed, R. Diversity and characterization of endophytic fungi isolated from the tropical mangrove species, Rhizophora mucronata, and identification of potential antagonists against the soil-borne fungus, Fusarium solani. Front. Microbiol. 2018, 9, 1707. [CrossRef]

16. Al-Shibli, H.; Dobretsov, S.; Al-Nabhani, A.; Maharachchikumbura, S.S.N.; Rethinasamy, V.; Al-Sadi, A.M. Aspergillus terreus obtained from mangrove exhibits antagonistic activities against Pythium aphanidermatum-induced damping-off of cucumber. PeerJ 2019, 7, e7884. [CrossRef]

17. He, X.-T.; Traina, S.J.; Logan, T.J. Chemical properties of municipal solid waste composts. J. Environ. Qual. 1992, 21, 318-329. [CrossRef]

18. Harada, Y.; Inoko, A. The measurement of the cation-exchange capacity of composts for the estimation of the degree of maturity. Soil Sci. Plant Nutr. 1980, 26, 127-134. [CrossRef]

19. Nandi, M.; Selin, C.; Brawerman, G.; Fernando, W.G.D.; de Kievit, T. Hydrogen cyanide, which contributes to Pseudomonas chlororaphis strain PA23 biocontrol, is upregulated in the presence of glycine. Biol. Control. 2017, 108, 47-54. [CrossRef]

20. Ozimek, E.; Jaroszuk-Ściseł, J.; Bohacz, J.; Korniłłowicz-Kowalska, T.; Tyśkiewicz, R.; Słomka, A.; Nowak, A.; Hanaka, A. Synthesis of indoleacetic acid, gibberellic acid and ACC-deaminase by Mortierella strains promote winter wheat seedlings growth under different conditions. Int. J. Mol. Sci. 2018, 19, 3218. [CrossRef]

21. Malhotra, M.; Srivastava, S. Stress-responsive indole-3-acetic acid biosynthesis by Azospirillum brasilense SM and its ability to modulate plant growth. Eur. J. Soil Biol. 2009, 45, 73-80. [CrossRef]

22. Alori, E.T.; Glick, B.R.; Babalola, O.O. Microbial phosphorus solubilization and its potential for use in sustainable agriculture. Front. Microbiol. 2017, 8, 971. [CrossRef] [PubMed]

23. Ameen, F.; Moslem, M.; Hadi, S. Biodegradation of Urban Waste by Mangrove Fungi; Lap Lambert Academic Publishing GmbH \& Company KG: Saarbrücken, Germany, 2015; p. 236.

24. Khan, A.L.; Hamayun, M.; Kang, S.-M.; Kim, Y.-H.; Jung, H.-Y.; Lee, J.-H.; Lee, I.-J. Endophytic fungal association via gibberellins and indole acetic acid can improve plant growth under abiotic stress: An example of Paecilomyces formosus LHL10. BMC Microbiol. 2012, 12, 3. [CrossRef] [PubMed]

25. Mehmood, A.; Khan, N.; Irshad, M.; Hamayun, M.; Husna, I.; Javed, A.; Hussain, A. IAA producing endopytic fungus Fusariun oxysporum wlw colonize maize roots and promoted maize growth under hydroponic condition. Eur. Exp. Biol. $2018,8,24$. [CrossRef]

26. Waqas, M.; Khan, A.L.; Kamran, M.; Hamayun, M.; Kang, S.-M.; Kim, Y.-H.; Lee, I.-J. Endophytic fungi produce gibberellins and indoleacetic acid and promotes host-plant growth during stress. Molecules 2012, 17, 10754-10773. [CrossRef] 
27. Harman, G.E.; Howell, C.R.; Viterbo, A.; Chet, I.; Lorito, M. Trichoderma species-Opportunistic, avirulent plant symbionts. Nat. Rev. Microbiol. 2004, 2, 43-56. [CrossRef]

28. Sambrook, H.C. Molecular Cloning: A Laboratory Manual; Cold Spring Harbor: New York, NY, USA, 1989.

29. Ameen, F.; AlYahya, S.A.; AlNadhari, S.; Alasmari, H.; Alhoshani, F.; Wainwright, M. Phosphate solubilizing bacteria and fungi in desert soils: Species, limitations and mechanisms. Arch. Agron. Soil Sci. 2019, 65, 1446-1459. [CrossRef]

30. Maria, G.L.; Sridhar, K.R.; Raviraja, N.S. Antimicrobial and enzyme activity of mangrove endophytic fungi of southwest coast of India. J. Agric. Technol. 2005, 1, 67-80.

31. White, T.J.; Bruns, T.; Lee, S.; Taylor, J.W. Amplification and direct sequencing of fungal ribosomal RNA genes for phylogenetics. Pcr. Protoc. A Guide Methods Appl. 1990, 18, 315-322.

32. Iqbal, M.K.; Nadeem, A.; Sherazi, F.; Khan, R.A. Optimization of process parameters for kitchen waste composting by response surface methodology. Int. J. Environ. Sci. Technol. 2015, 12, 1759-1768. [CrossRef]

33. RStudio Team. Integrated Development for R; RStudio, Inc.: Boston, MA, USA, 2015.

34. Mu, D.; Horowitz, N.; Casey, M.; Jones, K. Environmental and economic analysis of an in-vessel food waste composting system at Kean University in the US. Waste Manag. 2017, 59, 476-486. [CrossRef] [PubMed]

35. De Corato, U. Agricultural waste recycling in horticultural intensive farming systems by on-farm composting and compost-based tea application improves soil quality and plant health: A review under the perspective of a circular economy. Sci. Total Environ. 2020, 738, 139840. [CrossRef] [PubMed]

36. Alessi, A.; Lopes, A.d.C.P.; Müller, W.; Gerke, F.; Robra, S.; Bockreis, A. Mechanical separation of impurities in biowaste: Comparison of four different pretreatment systems. Waste Manag. 2020, 106, 12-20. [CrossRef] [PubMed]

37. Almahasheer, H. High levels of heavy metals in Western Arabian Gulf mangrove soils. Mol. Biol. Rep. 2019, 46, 1585-1592. [CrossRef] [PubMed]

38. Al-Homaidan, A.A.; Al-Ghanayem, A.A.; Al-Qahtani, H.S.; Al-Abbad, A.F.; Alabdullatif, J.A.; Alwakeel, S.S.; Ameen, F. Effect of sampling time on the heavy metal concentrations of brown algae: A bioindicator study on the Arabian Gulf coast. Chemosphere 2020, 263, 127998. [CrossRef]

39. Ameen, F.; Hadi, S.; Moslem, M.; Al-Sabri, A.; Yassin, M.A. Biodegradation of engine oil by fungi from mangrove habitat. J. Gen. Appl. Microbiol. 2015, 61, 185-192. [CrossRef]

40. Ameen, F.; Moslem, M.; Hadi, S.; Al-Sabri, A.E. Biodegradation of diesel fuel hydrocarbons by mangrove fungi from Red Sea Coast of Saudi Arabia. Saudi J. Biol. Sci. 2016, 23, 211-218. [CrossRef]

41. Ameen, F.; Moslem, M.A.; Hadi, S.; Al-Sabri, A. Biodegradation of cellulosic materials by marine fungi isolated from South Corniche of Jeddah, Saudi Arabia. J. Pure Appl. Microbiol. 2014, 8, 3617-3626.

42. Ameen, F.; Moslem, M.; Hadi, S.; Al-Sabri, A.E. Biodegradation of Low Density Polyethylene (LDPE) by Mangrove Fungi From the Red Sea Coast. Prog. Rubber Plast. Recycl. Technol. 2015, 31, 125. [CrossRef]

43. Anjum, M.; Miandad, R.; Waqas, M.; Ahmad, I.; Alafif, Z.O.A.; Aburiazaiza, A.S.; Barakat, M.A.; Akhtar, T. Solid waste management in Saudi Arabia: A review. J. Appl. Agric. Biotechnol. 2016, 1, 13-26.

44. Moosa, A.; Sahi, S.T.; Haq, I.-U.; Farzand, A.; Khan, S.A.; Javaid, K. Antagonistic potential of Trichoderma isolates and manures against Fusarium wilt of tomato. Int. J. Veg. Sci. 2017, 23, 207-218. [CrossRef]

45. Suárez-Estrella, F.; Vargas-Garcia, C.; Lopez, M.J.; Capel, C.; Moreno, J. Antagonistic activity of bacteria and fungi from horticultural compost against Fusarium oxysporum f. sp. melonis. Crop. Prot. 2007, 26, 46-53. [CrossRef]

46. Özer, N.; Köycü, N.D. The ability of plant compost leachates to control black mold (Aspergillus niger) and to induce the accumulation of antifungal compounds in onion following seed treatment. BioControl 2006, 51, 229-243. [CrossRef]

47. Postma, J.; Nijhuis, E.H. Pseudomonas chlororaphis and organic amendments controlling Pythium infection in tomato. Eur. J. Plant Pathol. 2019, 154, 91-107. [CrossRef]

48. Al-Dhabi, N.A.; Esmail, G.A.; Mohammed Ghilan, A.-K.; Valan Arasu, M. Composting of Vegetable Waste Using Microbial Consortium and Biocontrol Efficacy of Streptomyces Sp. Al-Dhabi 30 Isolated from the Saudi Arabian Environment for Sustainable Agriculture. Sustainability 2019, 11, 6845. [CrossRef] 